\title{
T-Cell Differentiation
}

National Cancer Institute

\section{Source}

National Cancer Institute. T-Cell Differentiation. NCI Thesaurus. Code C19055.

Development of bone marrow-derived stem cells in the thymus through stages of positive selection under the influence of epithelial cells in the thymic cortex and negative selection under the influence of bone marrow-derived dendritic cells at the corticomedullary junction. Thymic T cell precursors (thymocytes) progress through phases expressing both CD4 and CD8 coreceptors to a sing le positive stage expressing only CD4 or CD8 in addition to the T cell receptor. They are then allowed to leave the thymus and enter the periphery via the lymphatics or venules of the circulatory system as mature T cells. (NCl/OSP) 